\title{
Image-enhanced endoscopy for gastric preneoplastic conditions and neoplastic lesions: a systematic review and meta-analysis
}

\author{
Authors \\ Institutions \\ 1 Gastroenterology Department, Portuguese Oncology \\ Institute of Porto, Porto, Portugal \\ 2 Department of Medical-Surgical Sciences and \\ Translational Medicine, Sant'Andrea Hospital, Sapienza \\ University of Rome, Rome, Italy \\ 3 MEDCIDS - Department of Community Medicine, \\ Information and Decision in Health, Faculty of Medicine, \\ University of Porto, Porto, Portugal \\ 4 Surgery and Physiology Department, Faculty of \\ Medicine, University of Porto, Porto, Portugal
}

Marta Rodríguez-Carrasco¹, Gianluca Esposito², Diogo Libânio ${ }^{1,3}$, Pedro Pimentel-Nunes ${ }^{1,3,4}$, Mário Dinis-Ribeiro ${ }^{1,3}$

submitted 6.3.2020

accepted after revision 28.5 .2020

published online 26.10 .2020

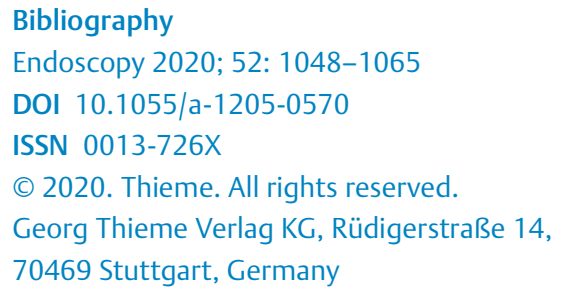

\section{Corresponding author}

Marta Rodríguez-Carrasco, MD, Gastroenterology Department, Portuguese Oncology Institute of Porto, Rua Dr. Bernardino de Almeida, 4200-072 Porto, Portugal Fax: + 351-22-5513646 martarc7@gmail.com

\section{Supplementary material}

Online content viewable at:

https://doi.org/10.1055/a-1205-0570

\section{ABSTRACT}

Background Image-enhanced endoscopy (IEE) improves the accuracy of endoscopic diagnosis. We aimed to assess the value of IEE for gastric preneoplastic conditions and neoplastic lesions.

Methods Medline and Embase were searched until December 2018. Studies allowing calculation of diagnostic measures were included. Risk of bias and applicability were assessed using QUADAS-2. Subgroup analysis was performed to explore heterogeneity.

Results 44 studies met the inclusion criteria. For gastric intestinal metaplasia (GIM), narrow-band imaging (NBI) obtained a pooled sensitivity and specificity of $0.79(95 \% \mathrm{Cl}$ $0.72-0.85)$ and 0.91 ( $95 \% \mathrm{Cl} 0.88-0.94)$ on per-patient basis; on per-biopsy basis, it was $0.84(95 \% \mathrm{Cl} 0.81-0.86)$ and 0.95 ( $95 \% \mathrm{Cl} 0.94-0.96)$, respectively. Tubulovillous pattern was the most accurate marker to detect GIM and it was effectively assessed without high magnification. For dysplasia, NBI showed a pooled sensitivity and specificity of 0.87 (95\% $\mathrm{Cl} 0.84-0.89)$ and $0.97(95 \% \mathrm{Cl} 0.97-0.98)$ on perbiopsy basis. The use of magnification improved the performance of NBI to characterize early gastric cancer (EGC), especially when the vessel plus surface (VS) classification was applied. Regarding other technologies, trimodal imaging also obtained a high accuracy for dysplasia (sensitivity $0.93[95 \% \mathrm{Cl} 0.85-0.98]$, specificity 0.98 [95\% Cl $0.92-$ $1.00])$. For atrophic gastritis, no specific pattern was noted and none of the technologies reached good diagnostic yield.

Conclusion NBI is highly accurate for GIM and dysplasia. The presence of tubulovillous pattern and the VS classification seem to be useful to detect GIM and characterize EGC, respectively. These features should be used in current practice and to standardize endoscopic criteria for other technologies.

\section{Introduction}

The emergence of image-enhanced endoscopy (IEE) in recent years has improved the performance of endoscopy, particularly with the development of virtual chromoendoscopy $[1,2]$, whose main advantages are its availability and simplicity, a demonstrated learning curve [3], and the accomplishment of a better characterization of the mucosal pattern. Moreover, it al- lows endoscopists to increasingly rely on imaging diagnosis, while decreasing the necessity to perform multiple biopsies [4].

Most of the studies have focused on narrow-band imaging (NBI) technology, with favorable results [5-12]. For instance, Kikuste et al. showed, in a meta-analysis, a pooled sensitivity and specificity of 0.87 and 0.77 for gastric intestinal metaplasia (GIM), and 0.90 and 0.83 for dysplasia [13]. Nevertheless, this meta-analysis was performed some years ago, and there is less 
evidence regarding the diagnostic accuracy of other technologies. Furthermore, there is a lack of standardization of mucosal patterns for some preneoplastic conditions and, with the advent of artificial intelligence (AI), it is of paramount importance to clearly identify the descriptors that should be used in clinical practice, because this technology is pattern-learning based.

We aimed to analyze the current evidence regarding virtual chromoendoscopy for the detection of gastric preneoplastic conditions (atrophic gastritis/GIM), lesions (dysplasia), and early gastric cancer (EGC), and to identify the factors that influence its accuracy.

\section{Methods}

\section{Search strategy}

Two electronic databases (MEDLINE through PubMed, and Embase) were searched up to December 2018. The search query for PubMed was: ((chromoendoscop* OR nbi OR "narrow band imaging" OR "Narrow Band Imaging"[Mesh] OR fice OR "flexible spectral imaging color enhancement" OR confocal OR bli OR "blue laser imaging" OR Ici OR "linked color imaging" OR afi OR "autofluorescence imaging" OR i-scan)) AND ((()(((gastric [ti] AND intestinal [ti] AND metaplasia [ti]) OR "gastric intestinal metaplasia" OR "intestinal metaplasia" OR (intestinal [ti] AND metaplasia [ti]))) OR ("gastric superficial neoplastic lesions" OR (gastric [ti] AND superficial [ti] AND neoplastic [ti] AND lesion* [ti]))) OR ("gastric precancerous lesions" OR "precancerous lesions" OR (gastric [ti] AND precancerous [ti] AND lesion*[ti]))) OR ("gastric preneoplastic lesions" OR (gastric [ti] AND preneoplastic [ti] AND lesion*[ti]))) OR "Stomach Neoplasms"[Mesh]) NOT (((esophagus) NOT (gastric AND esophagus $)))$ ). This query was adapted for the Embase database (Appendix 1s, see online-only Supplementary Material).

The protocol of this study is under revision in the PROSPERO platform (www.crd.york.ac.uk/prospero/, ID 154344). This systematic review was performed according to the PRISMA guideline for diagnostic test accuracy studies (Table 1s).

\section{Study selection}

\section{Eligibility criteria}

The inclusion criteria were: original articles whose primary or secondary outcome included accuracy/sensitivity/specificity of IEE for detection of premalignant conditions or EGC. Exclusion criteria were: case reports, meta-analyses, reviews, letters, comments, congress abstracts, guidelines, studies on animals, studies with fewer than 10 cases, studies published in languages other than English/Spanish/Portuguese/Italian, and studies with unavailable statistical data for true positive, true negative, false positive, and false negative determination.

After removing duplicates and overlapping publications, two authors (M.R.C., G.E.) independently screened the titles and abstracts, and irrelevant studies were excluded. The full text of the selected studies was evaluated by the same two authors, according to the inclusion and exclusion criteria. Disagreements were resolved through discussion with a third au- thor (D.L.). This step was performed using the Covidence online platform (www.covidence.org).

\section{Data extraction and quality evaluation}

Data extraction was performed by M.R.C. and checked by G.E. The following variables were collected: (1) author; (2) publication year; (3) country; (4) study period; (5) study design; (6) participants' characteristics (number of patients included; number of lesions/areas biopsied; age; sex); (7) endoscope system; (8) IEE technology assessed (NBI, AFI [autofluorescence imaging], TMI [TriModal Imaging], i-SCAN, FICE [flexible spectral imaging color enhancement], BLI [blue laser imaging], $\mathrm{LCl}$ [linked color imaging]); (9) mucosal and vascular pattern descriptors; (10) comparator; (11) outcome (atrophic gastritis/ GIM/dysplasia/EGC); (12) analysis performed (per-patient, perbiopsy/lesions); and (13) diagnostic accuracy measures (sensitivity, specificity, negative predictive value [NPV], positive predictive value [PPV], true positive, true negative, false positive, false negative, diagnostic accuracy, positive likelihood ratio, odds ratio). The reference standard was histology. Risk of bias and applicability were assessed by M.R.C. using the Quality Assessment of Diagnostic Accuracy Studies, second version (QUADAS-2).

\section{Data synthesis and statistical analysis}

Each IEE technology and gastric condition (atrophic gastritis/ GIM/dysplasia/EGC) were analyzed individually, considering per-patient or per-biopsy analysis. Accuracy measures were extracted from each study using a $2 \times 2$ contingency table. When possible, pooled measures (sensitivity, specificity, positive likelihood ratio, diagnostic odds ratio) with their respective $95 \%$ confidence intervals $(\mathrm{Cls})$, and summary receiver operating curve were calculated.

Heterogeneity was investigated with the Cochran's $Q$ test $(P<0.10$ meaning statistically significant heterogeneity) and $P$ (values of $R^{2} 0-25 \%, 25 \%-50 \%, 50 \%-75 \%$, and $>75 \%$ represented absent, low, moderate, and high levels of heterogeneity, respectively). When heterogeneity was absent, a fixed-effect model was used for meta-analysis. Otherwise, measures were calculated using a random-effect model. Possible sources of heterogeneity were explored by performing subgroup analysis considering the use of white-light endoscopy (WLE) before IEE, the use of high magnification, the most used mucosal pattern descriptors, and the morphology of lesions assessed. Analyses were performed using Meta-DiSc software (version 1.4).

\section{Results}

In total, 1338 studies were identified and 44 were selected for inclusion ( $\triangleright$ Fig. 1), with a total of 10175 patients and 10451 areas biopsied. Twenty-nine studies evaluated NBI, eight AFI/ TMI (one of them included an arm with high magnification NBI [ME-NBI] that was additionally considered for the NBI analysis), one i-SCAN, one FICE, three BLI, and two LCl. - Table 1 summarizes the baseline characteristics of each of the studies included $[9,14-56]$. The majority of them were performed in Eastern countries and had prospective recruitment. WLE was 


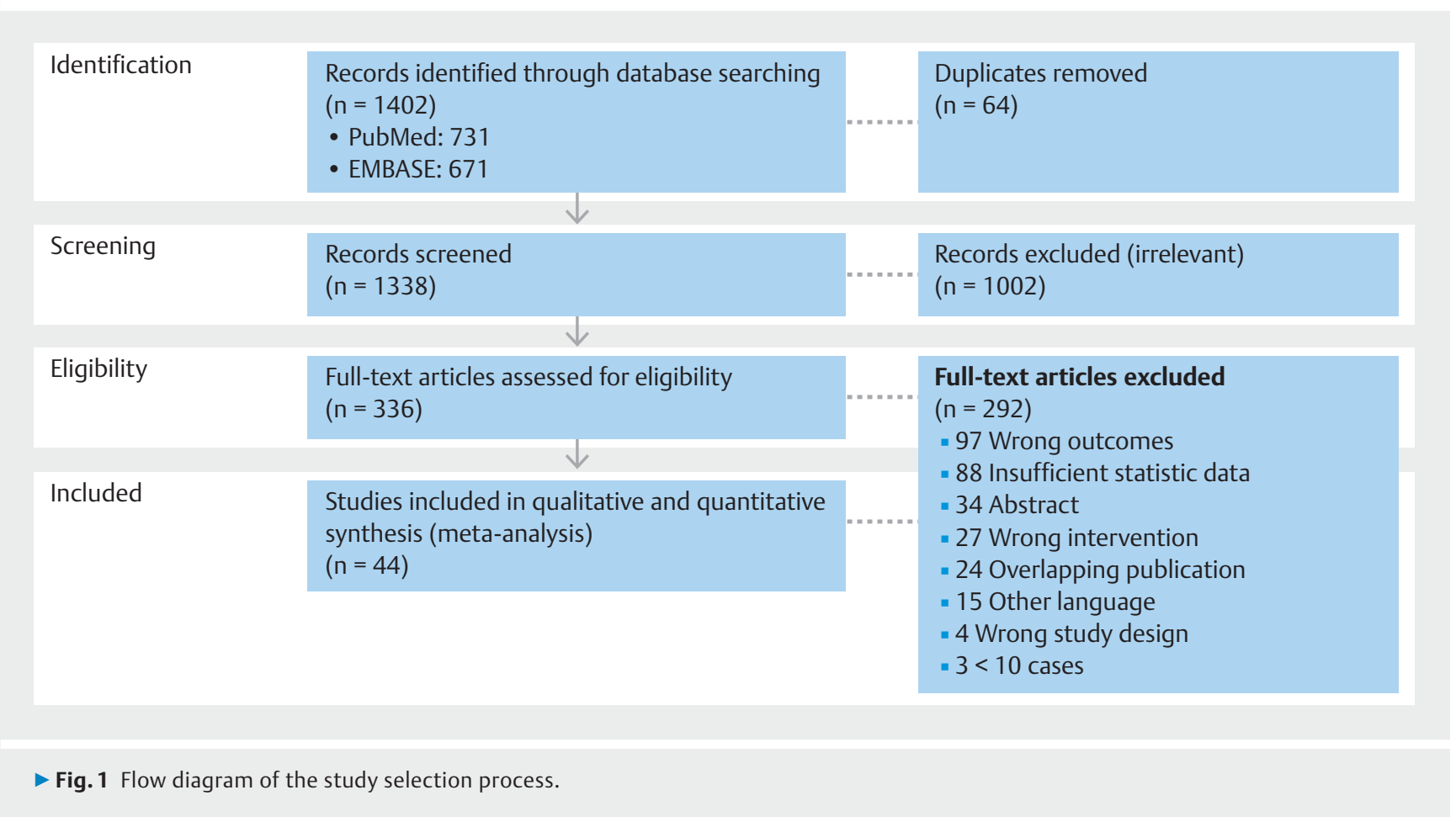

used before IEE in 33 studies, and high magnification was performed in 30 studies. There were 25 studies that compared results from IEE with WLE, and seven that compared different IEE techniques. The gold standard in all studies was histology.

- Table 2 summarizes the endoscopic descriptors used for each gastric condition. The most evaluated outcome was dysplasia/EGC. None of the studies reported a specific pattern for atrophic gastritis. Regarding GIM, the most used markers were the presence of tubulovillous pattern and "light-blue crest" (LBC) ( $\triangleright$ Fig. 2a). Some discrepancies concerning the LBC concept were noticed: despite it originally being defined under high magnification [5], only half of the studies applied high magnification, and some of the non-magnification studies still used the LBC concept but with a different description. Regarding dysplastic lesions, the most used sign was the presence of irregular microsurface/microvascular pattern (independently of the presence of a demarcation line) ( $\vee$ Fig. $2 \mathbf{b}$ ).

\section{Quality assessment}

The quality assessments of the included studies are shown in Table 2s and Fig. 1s. Each study was judged for risk of bias and applicability concerns, and was classified as "low risk" when considered "low" in all domains, "high risk" when one or more domains were considered "high," and "unclear" when insufficient data were reported. Almost half of the studies (52\%) showed high risk of bias on patient selection, mainly because they included very select population/gastric area/lesions (e. g. enriched population, only one gastric area assessed, depressed lesions, lesions $<10 \mathrm{~mm}$ ). Concerning other domains, the majority of studies presented low risk of bias, although $34 \%$ of studies demonstrated unclear risk with regard to the reference standard (mostly because of uncertainty of blinding). Almost all studies showed low concerns relating to applicability. Subgroup analysis according to study quality was not possible owing to the low number of studies in each subgroup.

\section{Diagnostic characteristics of different IEE technologies}

- Table 3 and $>$ Table 4 show pooled analysis for GIM and dysplasia/EGC. The detailed non-pooled measures from each study are shown for atrophic gastritis (Table 3s), GIM (Table 4s), and dysplasia/EGC (Table 5s) (owing to the low number of studies included in some groups, it was not possible to conduct a pooled analysis in all of them).

\section{$\mathrm{NBI}$}

Thirty studies were selected for analysis, including a total of 8482 patients. It was only possible to perform pooled analysis for GIM and EGC.

Atrophic gastritis: Two studies evaluated the presence of atrophic gastritis $[14,15]$. The endoscopic criteria for atrophic gastritis were the same as those used for GIM; however, for atrophic gastritis, the sensitivities were significantly lower compared with those for GIM.

GIM: Fourteen studies reported their results regarding GIM [9, 14-26].

- Per-patient analysis: the pooled sensitivity and specificity from the six studies included were $0.79(95 \% \mathrm{Cl} 0.72-0.85)$ and 0.91 ( $95 \% \mathrm{Cl} 0.88-0.94)$, with moderate to high heterogeneity. In the three studies that used ME-NBI, heterogeneity was absent to moderate, and the pooled specificity was significantly higher compared with the non-ME-NBI subgroup (0.97 [95\% Cl 0.92-0.99] vs. 0.89 [95\% Cl 0.84-0.92]). 


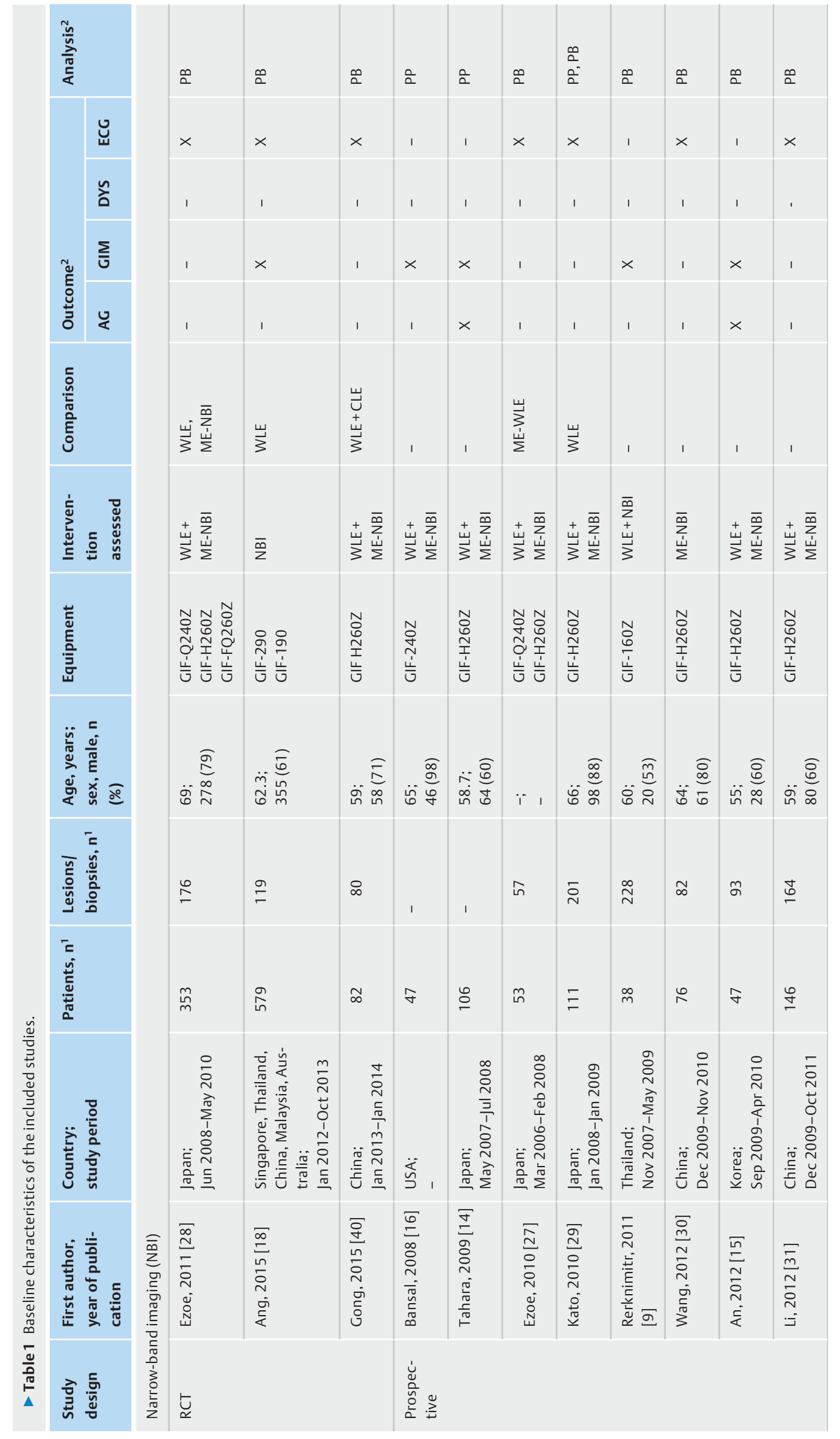



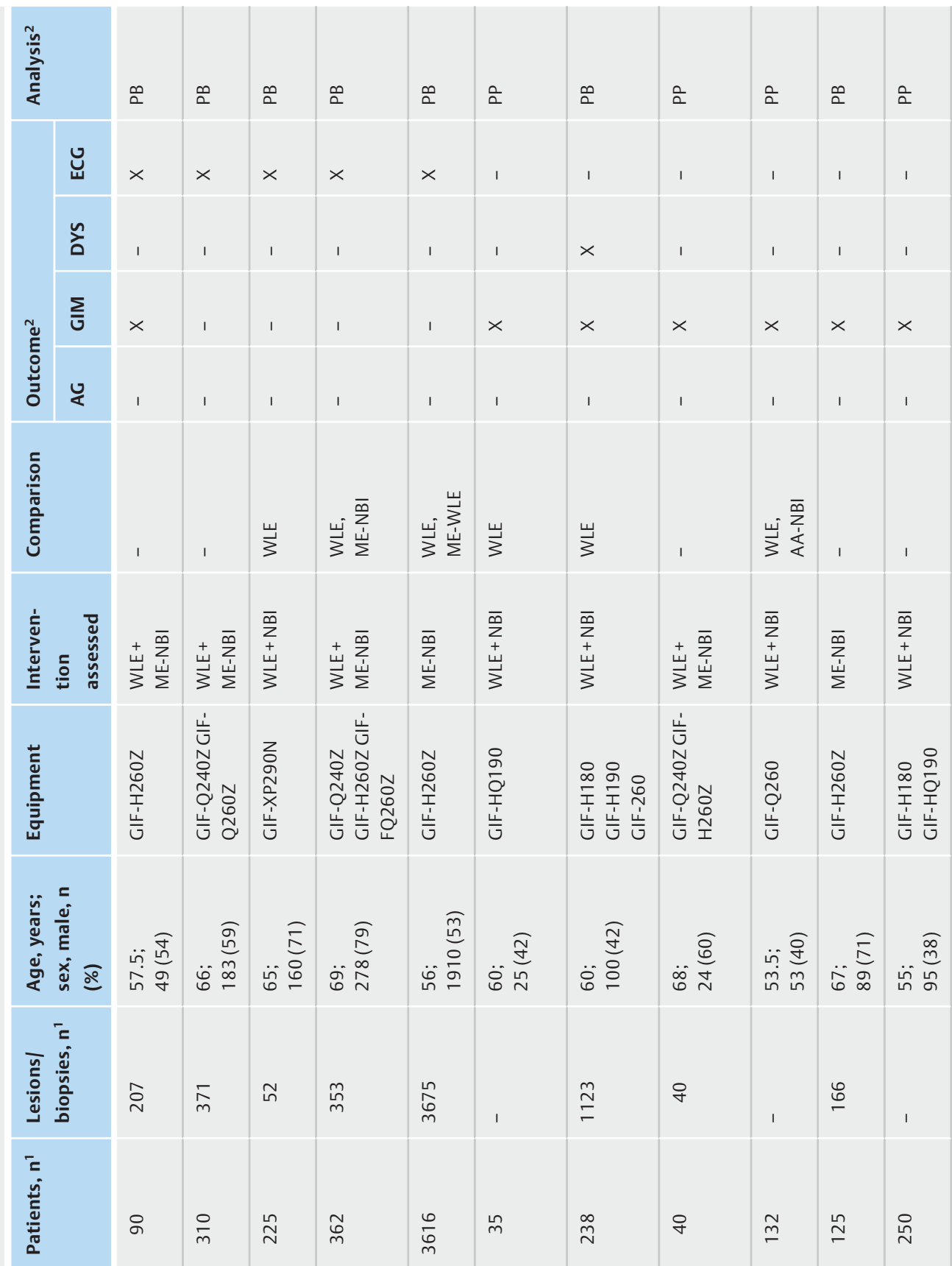

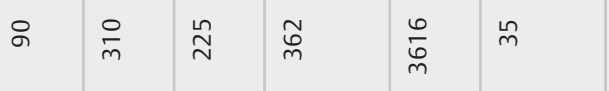

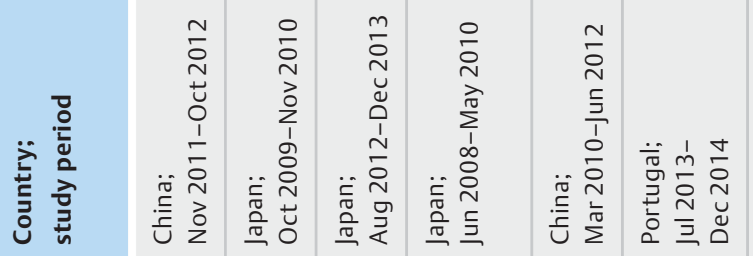

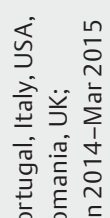

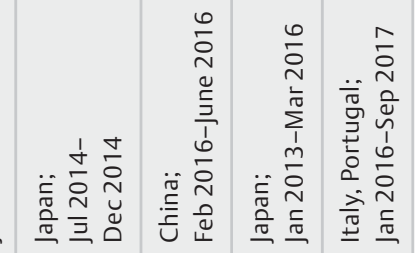

है

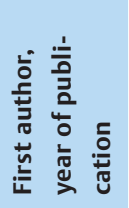

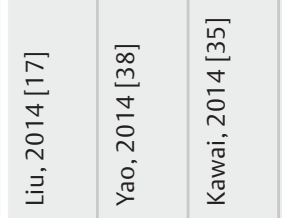

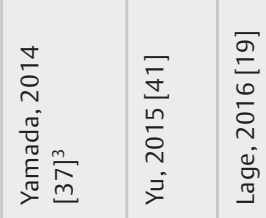

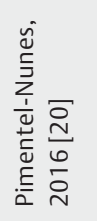

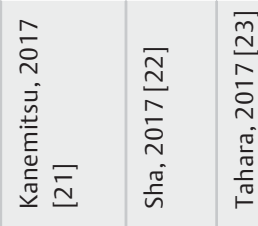

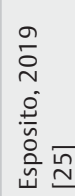

$\frac{\sqrt{0}}{\frac{0}{10}}$ 


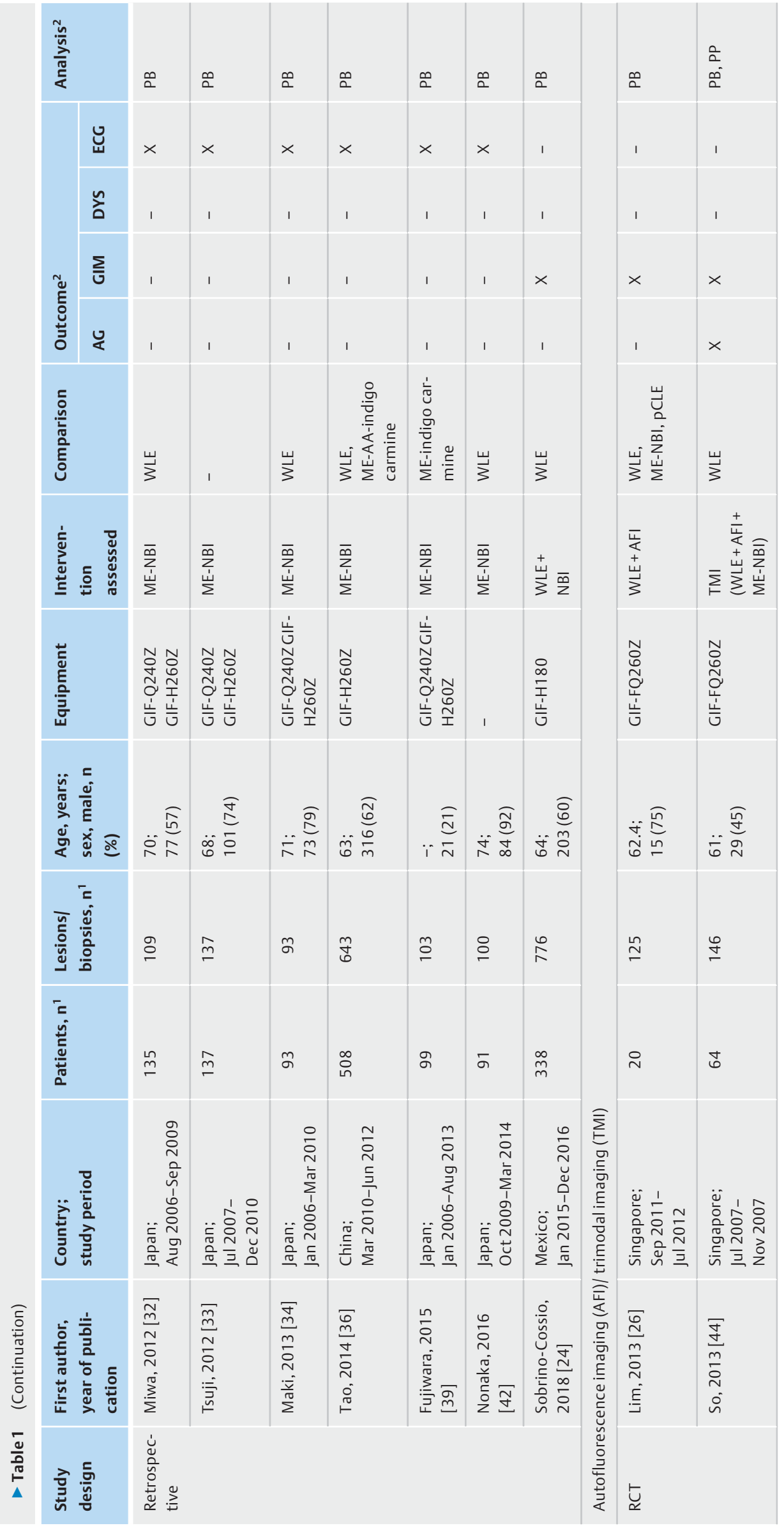




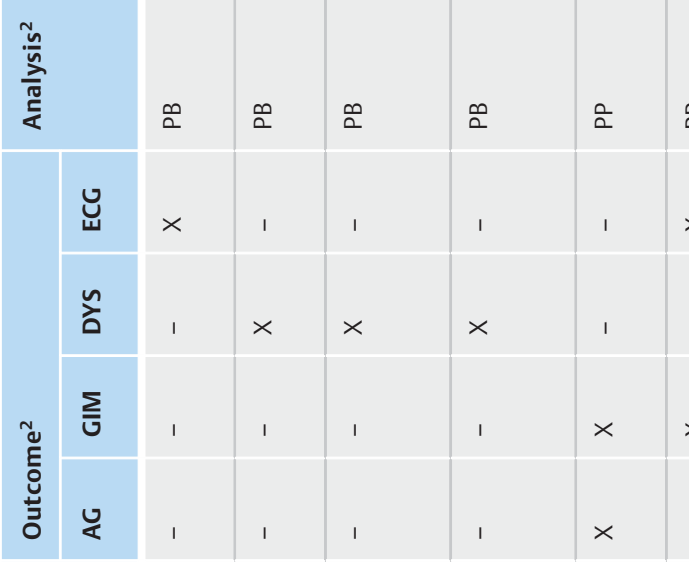

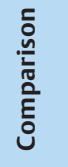

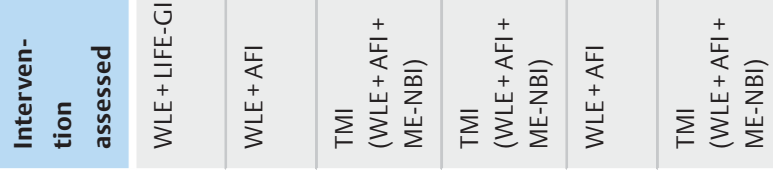

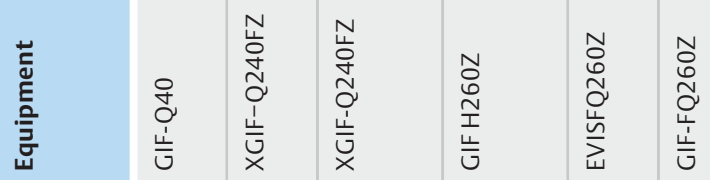

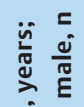

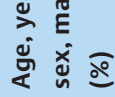

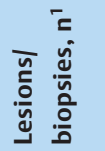

¿ह

ก

$\underset{\hat{i}}{\stackrel{0}{\infty}}$

$\underset{\frac{\infty}{\sqrt{\infty}}}{2}$

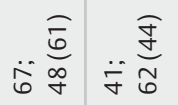

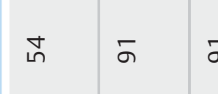

$\stackrel{n}{2}$

$\stackrel{\leftrightarrow}{\sim}$

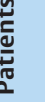

古
范高

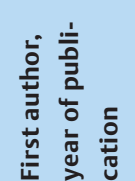

$$
\left(\frac{1}{2}\right.
$$



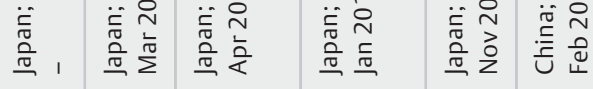

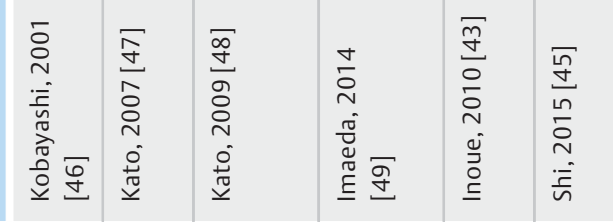

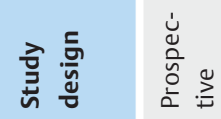

$\cong \cong$ ๓

岁

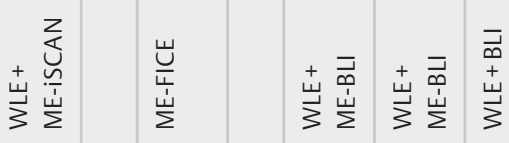

$\bar{i}$
Oे
ஸे
U.

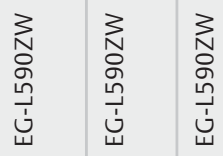

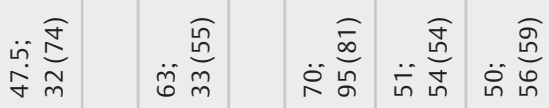

$\stackrel{2}{\simeq}$

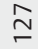

ํํ용

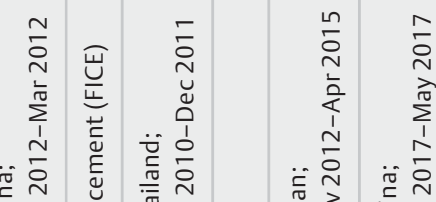

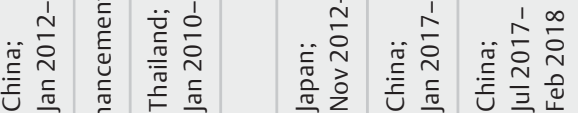

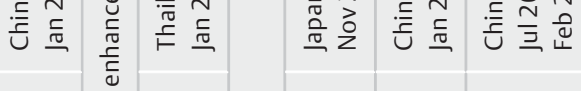

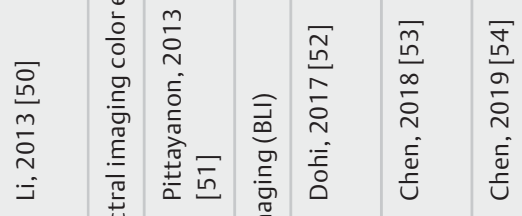

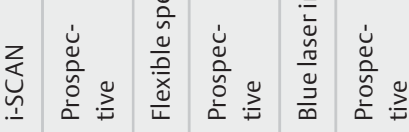




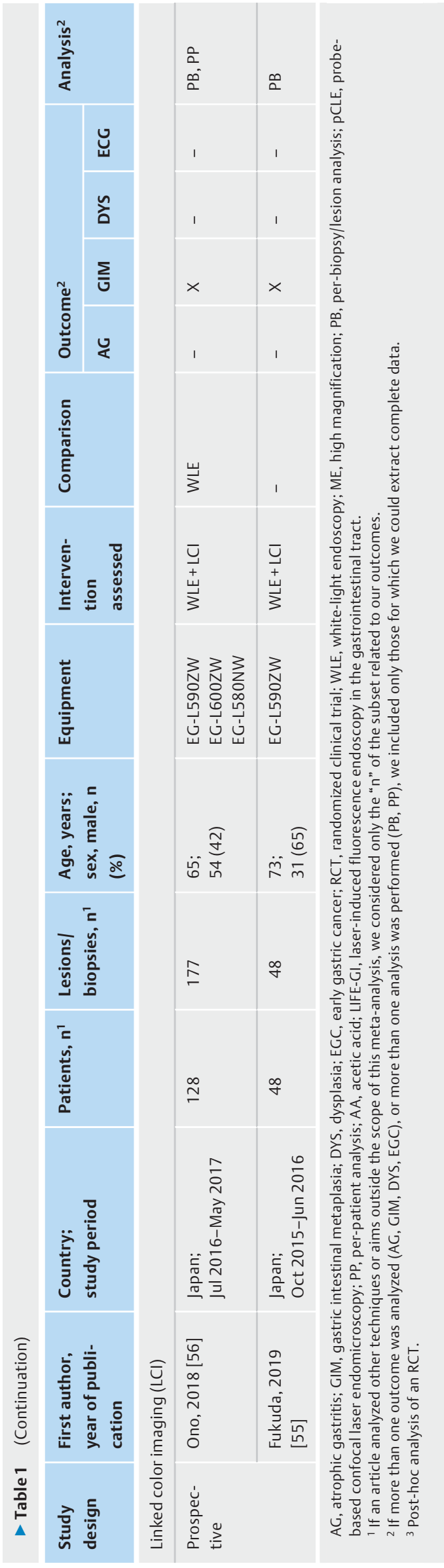

- Per-biopsy analysis: from the nine studies included, the pooled sensitivity and specificity were 0.84 (95\%Cl $0.81-$ 0.86 ) and 0.95 ( $95 \% \mathrm{Cl} 0.94-0.96)$, with high heterogeneity. Subgroup analysis according to ME-NBI use did not influence accuracy or heterogeneity.

Under high magnification, we found that using LBC as the only marker for GIM was associated with a lower specificity compared with the use of other patterns or a combination of endoscopic markers $(0.89$ [ $95 \% \mathrm{Cl} 0.82-0.94]$ vs. 0.96 [ $95 \% \mathrm{Cl} 0.94-$ $0.98]$, high heterogeneity); however, only two studies were included in each subgroup. In the studies without high magnification, accuracy was significantly higher in the subgroup that used tubulovillous pattern with or without LBC on the per-biopsy analysis, and heterogeneity was absent to moderate (sensitivity and specificity of 0.88 [95\% Cl $0.84-0.90]$ and 0.97 [05\% Cl 0.96-0.98]) (• Fig.3).

Dysplasia and EGC: Nineteen articles evaluated the detection of dysplasia/EGC. One article performed two separate analyses based on morphology without conditioning overlapping data, so we included both of these, meaning a total of 20 studies were included $[17,18,20,27-42]$. In order to reduce heterogeneity, we only performed the analysis with those studies that aimed to discriminate cancerous (Vienna 4-5) vs. non-cancerous lesions (including Vienna 3). Studies regarding histological characterization of EGC were outside the scope of this meta-analysis.

- Per-biopsy analysis: the pooled sensitivity and specificity from the 19 studies included were 0.87 (95\% Cl 0.84-0.89) and 0.97 (95\% Cl 0.97-0.98), respectively, with high heterogeneity. Specificity was significantly higher in the ME-NBI subgroup (17 studies) at $0.97(95 \% \mathrm{Cl} 0.97-0.98)$ vs. 0.84 (95\% Cl 0.78-0.90) in the non-ME studies (2 studies; high heterogeneity). Morphology had a significant impact on the diagnostic accuracy, being higher in depressed-type lesions (sensitivity 0.88 [95\%Cl $0.80-0.93]$, specificity $0.96[95 \% \mathrm{Cl}$ 0.93-0.97]; absent to moderate heterogeneity).

In the studies with ME-NBI, the specificity was significantly higher in the subgroup that used the "vessel plus surface" (VS) classification ( $>$ Fig.4) (specificity 0.98 [95\%Cl $0.97-0.98]$ vs. 0.94 [95\% Cl 0.92-0.96]), although the sensitivity was lower $(0.86$ [ $95 \% \mathrm{Cl} 0.83-0.88]$ vs. 0.94 [ $95 \% \mathrm{Cl} 0.88-0.98])$, with high heterogeneity. The pooled specificity of the studies with WLE before ME-NBI was lower compared with those without WLE $(0.96$ [ $95 \% \mathrm{Cl} 0.95-0.97$ ] vs. 0.98 [ $95 \% \mathrm{Cl}$ 0.97-0.98]; high heterogeneity).

\section{AFI/TMI}

Eight studies were selected, including 649 patients. One study evaluated the laser-induced fluorescence endoscopy in the gastrointestinal tract (LIFE-GI) system, which represents the technological predecessor of AFI, and has a lower image quality. Four studies evaluated AFI combined with ME-NBI, which is recognized as trimodal imaging (TMI).

Atrophic gastritis: The presence of atrophic gastritis in the corpus was assessed in two studies $[43,44]$ : one evaluated AFI 
- Table 2 Pattern descriptors by condition and technology.

\begin{tabular}{|c|c|c|c|}
\hline $\begin{array}{l}\text { Use of high } \\
\text { magnification }\end{array}$ & Atrophic gastritis & Gastric intestinal metaplasia & Dysplasia/early gastric cancer \\
\hline \multicolumn{4}{|c|}{ Narrow-band imaging (NBI) } \\
\hline Yes & $\begin{array}{l}\text { LBC: a fine blue-white } \\
\text { line on the crest of the } \\
\text { epithelial surface/gyri } \\
\text { [15] } \\
\text { MTB: an enclosing white } \\
\text { turbid band on the epi- } \\
\text { thelial surface/gyri [15] } \\
\text { Oval or tubulovillous pit } \\
\text { with clearly visible coiled } \\
\text { or wavy vessels [14] }\end{array}$ & $\begin{array}{l}\text { LBC: a fine blue-white line on the crest of the } \\
\text { epithelial surface/gyri }[15,17,21,26] \\
\text { MTB: an enclosing white turbid band on the } \\
\text { epithelial surface/gyri [15] } \\
\text { Ridge/tubulovillous mucosal pattern }[16,17] \\
\text { Oval or tubulovillous pit with clearly visible } \\
\text { coiled or wavy vessels }[14,23] \\
\text { WOS: a white substance that renders the sube- } \\
\text { pithelial vasculature of the intervening part } \\
\text { surrounded by crypt openings opaque [21] }\end{array}$ & $\begin{array}{l}\text { VS classification: irregular microsurface and/or } \\
\text { microvascular pattern within a demarcation } \\
\text { line }[27,28,30,32-34,36-42] \\
\text { Demarcated lesions with a disappearance of } \\
\text { fine mucosal structure, microvascular dilation } \\
\text { and microvascular heterogeneity in shape [29] } \\
\text { Obscure irregular microsurface or microvascu- } \\
\text { lar pattern / no microsurface pattern and sparse } \\
\text { microvascular or avascular areas [31] } \\
\text { Demarcated lesions with disappearance of nor- } \\
\text { mal pit pattern and appearance of new vessels } \\
\text { [17] }\end{array}$ \\
\hline No & & $\begin{array}{l}\text { Ridge/tubulovillous mucosal pattern }[9,18- \\
20,24,25] \\
\text { LBC with different definitions: } \\
\text { A fine, blue-white line on the crests of the epi- } \\
\text { thelial surface }[9,18,24] \\
\text { Blue-whitish slightly raised areas }[9,20] \\
\text { LLC: a combination of linear dark and light areas } \\
\text { that differed from the normal gastric epithe- } \\
\text { lium [9] } \\
\text { Bluish-whitish areas with a regular mucosal } \\
\text { pattern [22] }\end{array}$ & $\begin{array}{l}\text { Irregular mucosal and vascular pattern }[18,20] \\
\text { VS classification [35] } \\
\text { WOS: a white material above the mucosa that } \\
\text { could be either well defined (regular) or not } \\
\text { (irregular) [20]. }\end{array}$ \\
\hline \multicolumn{4}{|c|}{ Autofluorescence imaging (AFI) } \\
\hline No & $\begin{array}{l}\text { Homogeneous green ap- } \\
\text { pearance in the gastric } \\
\text { body }[43,44]\end{array}$ & $\begin{array}{l}\text { Homogeneous green areas with a regular pat- } \\
\text { tern in the gastric body }[26,43,44]\end{array}$ & $\begin{array}{l}\text { Dark red or deep red changes }[45,46] \\
\text { Area with a defined margin and with a differ- } \\
\text { ence in color compared with the surrounding } \\
\text { mucosa [47-49] }\end{array}$ \\
\hline \multicolumn{4}{|l|}{ i-SCAN } \\
\hline Yes & - & - & $\begin{array}{l}\text { Surface pit pattern: irregular arrangement and } \\
\text { size or destructive pattern [50] }\end{array}$ \\
\hline \multicolumn{4}{|c|}{ Flexible spectral imaging color enhancement (FICE) } \\
\hline Yes & - & $\begin{array}{l}\text { Villous mucosal pattern [51] } \\
\text { LBC: a fine blue-white line on the crest of the } \\
\text { epithelial surface [51] } \\
\text { LLC: a combination of linear dark and light } \\
\text { areas [51] }\end{array}$ & - \\
\hline \multicolumn{4}{|c|}{ Blue laser imaging (BLI) } \\
\hline Yes & - & $\begin{array}{l}\text { Bluish-whitish patchy areas with a regular mu- } \\
\text { cosal pattern [53] }\end{array}$ & $\begin{array}{l}\text { Irregular microsurface or microvascular } \\
\text { pattern within a demarcation line [52] }\end{array}$ \\
\hline No & & $\begin{array}{l}\text { Bluish-whitish patchy areas with a regular mu- } \\
\text { cosal pattern [54] }\end{array}$ & \\
\hline \multicolumn{4}{|c|}{ Linked color imaging (LCI) } \\
\hline No & - & $\begin{array}{l}\text { Focal and patchy lesion with a lavender color } \\
\text { that was distinguished from the surrounding } \\
\text { area [55], defined as "lavender-color sign" [56] }\end{array}$ & - \\
\hline \multicolumn{4}{|l|}{ Summary } \\
\hline & To be better defined & $\begin{array}{l}\text { Tubulovillous pattern is the most consistent } \\
\text { endoscopic marker and improves accuracy } \\
\text { values }\end{array}$ & $\begin{array}{l}\text { Irregular microsurface and/or microvascular } \\
\text { pattern are consistently a sign of dysplasia/ } \\
\text { cancer }\end{array}$ \\
\hline
\end{tabular}

LBC, light-blue crest; MTB, marginal turbid band; LLC, large long crest; WOS, white opaque substance; VS classification, vessel plus surface classification, according to Yao et al. [57]. 


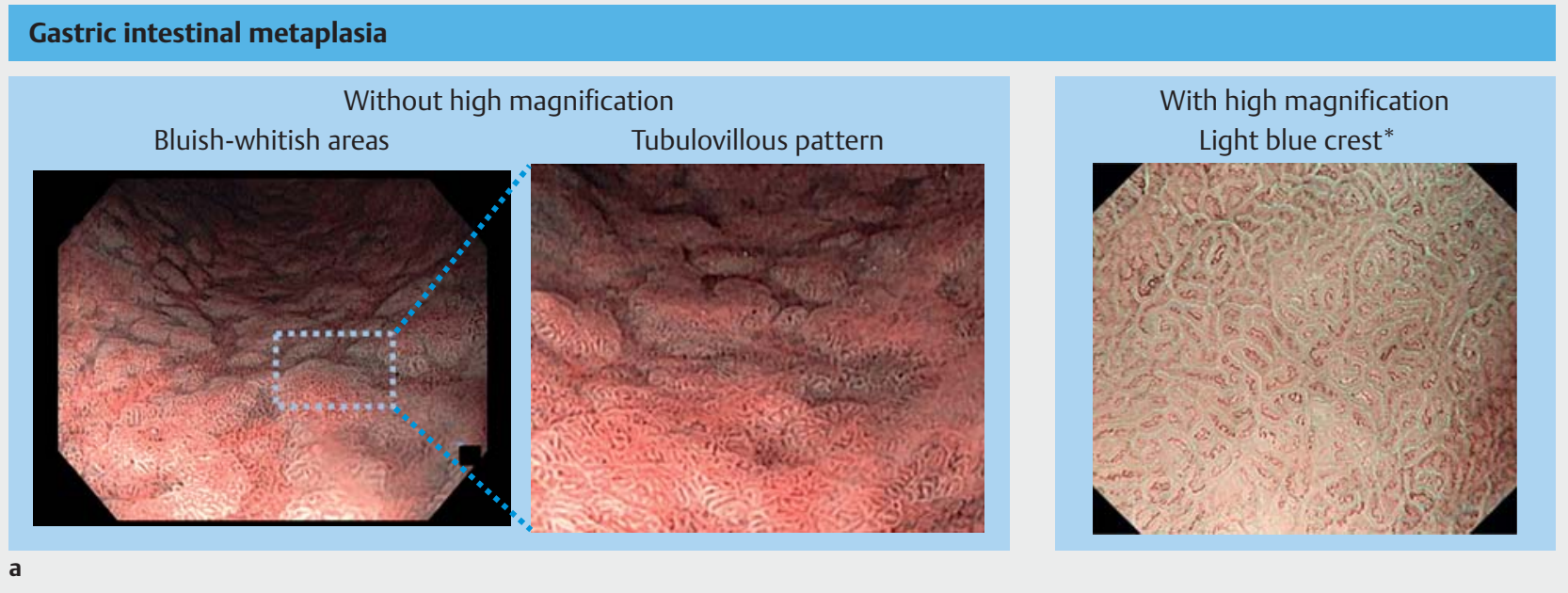

\section{Early gastric cancer}

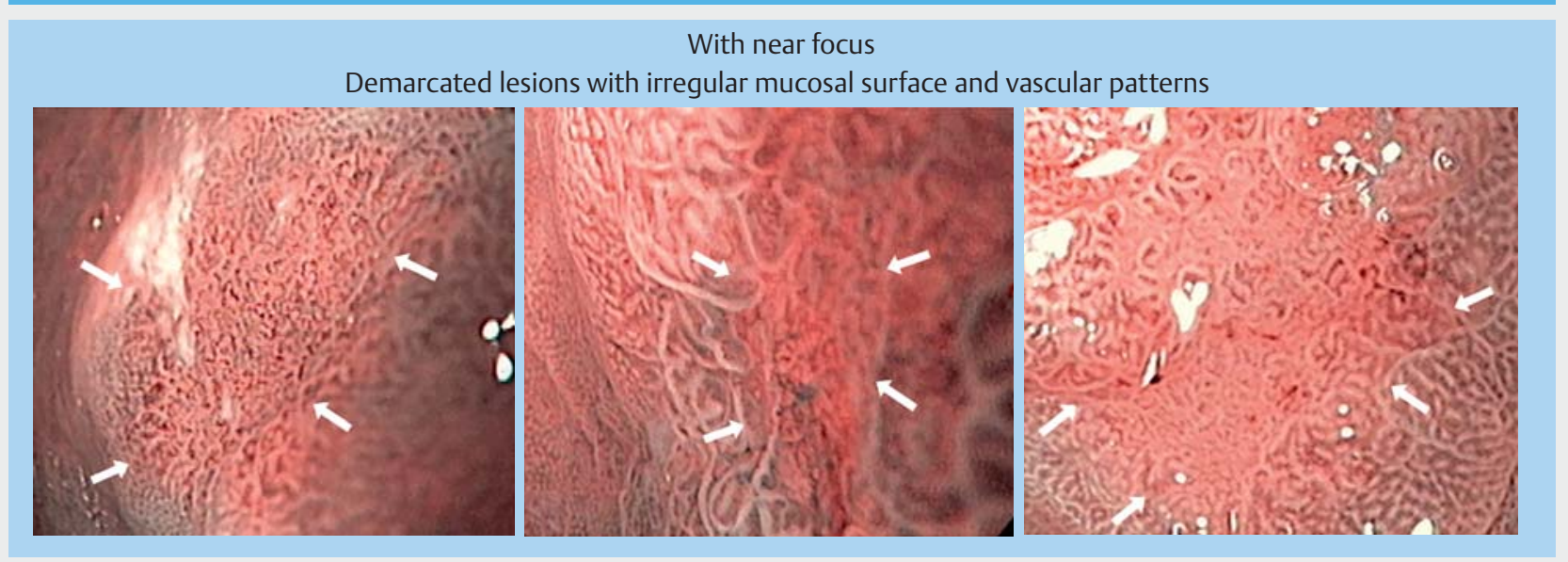

b

- Fig. 2 Representative images of the principal markers of gastric intestinal metaplasia and early gastric cancer. Some of the images were previously published in Endoscopy [21] and in Endoscopy International Open [4], and were used in this systematic review with the permission of the Editorial Board.

* Endoscopic description according to Uedo's definition [5].

on a per-patient basis; the other evaluated TMI on a per-patient and per-biopsy basis. Although the results were variable, the studies showed a very low sensitivity and an intermediate specificity.

GIM: Four studies assessed GIM [26,43-45]. Although the overall accuracy was slightly higher for AFI compared with TMI, this was not statistically significant. One TMI study showed very poor specificity [44], and the authors speculated that the reason for this could be mostly down to their limited experience in interpreting ME-NBI images.

Dysplasia/EGC: Among the five included studies [45-49], pooled analysis was only possible for two of them. Both studies evaluated the presence of dysplasia with TMI, showing a sensitivity and specificity of 0.93 and 0.98 , respectively. In general, studies with TMI obtained better results, chiefly improving the sensitivity.

\section{i-SCAN}

One study evaluated the accuracy of ME-i-SCAN in the diagnosis of cancerous lesions (43 patients/lesions) [50]. Although the sensitivity was very high (1.00), the specificity was only acceptable (0.77) and the PPV was poor (0.50). The authors concluded that the value of ME-i-SCAN in the diagnosis of cancerous lesions is limited, because microvascular assessment remains unsatisfactory.

\section{FICE}

One study [51] compared ME-FICE with ME-FICE + pCLE (probed-based confocal laser endomicroscopy) in 60 patients. Although ME-FICE had a high sensitivity and specificity for GIM ( 0.96 and 0.80 , respectively), the addition of pCLE increased the specificity in $11 \%$. Therefore, the authors support the use of a combination of virtual chromoendoscopy with PCLE to characterize suspected GIM areas. 
Table 3 Pooled analysis of results for gastric intestinal metaplasia.

\begin{tabular}{|c|c|c|c|c|c|c|}
\hline Covariates & $\begin{array}{l}\text { Num- } \\
\text { ber of } \\
\text { stud- } \\
\text { ies }\end{array}$ & $\begin{array}{l}\text { Sensitivity } \\
(95 \% \mathrm{Cl})\end{array}$ & $\begin{array}{l}\text { Specificity } \\
(95 \% \mathrm{Cl})\end{array}$ & $\begin{array}{l}\text { Positive LR } \\
\text { (95\% Cl) }\end{array}$ & $\begin{array}{l}\text { DOR } \\
(95 \% \mathrm{Cl})\end{array}$ & $\begin{array}{l}\text { AUC } \\
(95 \% \mathrm{CI})\end{array}$ \\
\hline \multicolumn{7}{|c|}{ Narrow-band imaging (NBI): per-patient analysis } \\
\hline Overall & 6 & $0.79(0.72-0.85)$ & $0.91(0.88-0.94)$ & $12.37(3.66-41.83)$ & $65.65(11.04-390.41)$ & $0.9(0.77-1.03)$ \\
\hline \multicolumn{7}{|c|}{ High magnification (ME) } \\
\hline Overall & 3 & $0.82(0.67-0.92)$ & $0.97(0.92-0.99)$ & $17.78(6.69-47.25)$ & $86.40(26.71-279.5)$ & $0.95(0.83-1.07)$ \\
\hline Previous WLE & 3 & $0.82(0.67-0.92)$ & $0.97(0.92-0.99)$ & $17.78(6.69-47.25)$ & $86.40(26.71-279.5)$ & $0.95(0.83-1.07)$ \\
\hline $\begin{array}{l}\text { Non-previous } \\
\text { WLE }\end{array}$ & 0 & - & - & - & - & - \\
\hline $\begin{array}{l}\text { Villous } \\
\text { pattern }\end{array}$ & 2 & $0.75(0.51-0.91)$ & $0.97(0.93-0.99)$ & $21.41(8.45-54.28)$ & $78.00(20.02-303.87)$ & - \\
\hline $\begin{array}{l}\text { Non-villous } \\
\text { pattern }\end{array}$ & 1 & $0.87(0.68-0.92)$ & $0.94(0.70-1.00)$ & $14.00(2.09-93.95)$ & $105.00(9.93-1110.00)$ & - \\
\hline \multicolumn{7}{|l|}{ Non-ME } \\
\hline Overall & 3 & $0.78(0.69-0.84)$ & $0.89(0.84-0.92)$ & $8.11(1.44-45.68)$ & $45.85(2.56-822.13)$ & $0.67(0.55-0.79)$ \\
\hline Previous WLE & 3 & $0.78(0.69-0.84)$ & $0.89(0.84-0.92)$ & $8.11(1.44-45.68)$ & $45.85(2.56-822.13)$ & $0.67(0.55-0.79)$ \\
\hline $\begin{array}{l}\text { Non-previous } \\
\text { WLE }\end{array}$ & 0 & - & - & - & - & - \\
\hline $\begin{array}{l}\text { Villous pat- } \\
\text { tern +/ LBC }\end{array}$ & 2 & $0.90(0.79-0.96)$ & $0.95(0.91-0.97)$ & $17.14(9.63-30.53)$ & $157.58(56.28-441.25)$ & - \\
\hline $\begin{array}{l}\text { Non-villous } \\
\text { pattern +/ LBC }\end{array}$ & 1 & $0.67(0.54-0.78)$ & $0.68(0.56-0.79)$ & $2.10(1.42-3.10)$ & $4.29(2.07-8.88)$ & - \\
\hline \multicolumn{7}{|c|}{ Narrow-band imaging (NBI): per-biopsy analysis } \\
\hline Overall & 9 & $0.84(0.81-0.86)$ & $0.95(0.94-0.96)$ & $12.71(5.45-29.6)$ & $72.51(23.31-225.52)$ & $0.92(0.84-1.00)$ \\
\hline \multicolumn{7}{|c|}{ High magnification (ME) } \\
\hline Overall & 4 & $0.83(0.77-0.88)$ & $0.95(0.92-0.96)$ & $14.72(5.48-39.53)$ & $85.53(24.18-302.55)$ & $0.96(0.88-1.05)$ \\
\hline WLE & 3 & $0.78(0.71-0.85)$ & $0.93(0.89-0.96)$ & $10.09(4.25-23.94)$ & $42.75(22.67-80.61)$ & $0.92(0.87-0.97)$ \\
\hline Non-WLE & 1 & $0.96(0.86-0.99)$ & $0.98(0.94-1.00)$ & $56.11(14.18-221.98)$ & $1351.3(184.87-9876.5)$ & - \\
\hline LBC & 2 & $0.81(0.72-0.88)$ & $0.89(0.82-0.94)$ & $8.27(2.36-29.04)$ & $39.20(17.30-88.82)$ & - \\
\hline Non-LBC & 2 & $0.85(0.76-0.92)$ & $0.96(0.94-0.98)$ & $26.12(6.12-111.95)$ & $233.81(9.12-5997.8)$ & - \\
\hline \multicolumn{7}{|l|}{ Non-ME } \\
\hline Overall & 5 & $0.84(0.81-0.87)$ & $0.95(0.94-0.96)$ & $11.05(3.18-38.34)$ & $60.25(11.01-329.71)$ & $0.87(0.72-1.01)$ \\
\hline WLE & 4 & $0.84(0.81-0.87)$ & $0.95(0.94-0.96)$ & $10.24(2.46-42.70)$ & $46.60(6.67-325.36)$ & $0.79(0.66-0.93)$ \\
\hline Non-WLE & 1 & $0.92(0.82-0.98)$ & $0.94(0.85-0.98)$ & $15.46(5.96-40.12)$ & $189.00(44.96-794.43)$ & - \\
\hline $\begin{array}{l}\text { Villous pat- } \\
\text { tern +/ LBC }\end{array}$ & 3 & $0.88(0.84-0.90)$ & $0.97(0.96-0.98)$ & $29.03(17.73-47.52)$ & $224.28(148.63-338.43)$ & $0.97(0.95-1)$ \\
\hline $\begin{array}{l}\text { Non-villous } \\
\text { pattern + / LBC }\end{array}$ & 2 & $0.74(0.66-0.80)$ & $0.78(0.72-0.83)$ & $3.081(1.45-6.55)$ & $8.74(2.19-34.82)$ & - \\
\hline \multicolumn{7}{|c|}{ Autofluorescence imaging (AFI): per-patient analysis } \\
\hline $\begin{array}{l}\text { Without } \\
\text { ME-NBI }\end{array}$ & 2 & $0.86(0.77-0.92)$ & $0.82(0.74-0.88)$ & $3.82(1.00-14.59)$ & $27.04(11.05-66.19)$ & - \\
\hline $\begin{array}{l}\text { With ME-NBI } \\
\text { (TMI) }\end{array}$ & 2 & $0.80(0.69-0.88)$ & $0.77(0.68-0.84)$ & $3.03(0.15-59.52)$ & $7.50(0.062-910.64)$ & - \\
\hline
\end{tabular}


- Table 3 (Continuation)

\begin{tabular}{|c|c|c|c|c|c|c|}
\hline Covariates & $\begin{array}{l}\text { Num- } \\
\text { ber of } \\
\text { stud- } \\
\text { ies }\end{array}$ & $\begin{array}{l}\text { Sensitivity } \\
(95 \% \mathrm{CI})\end{array}$ & $\begin{array}{l}\text { Specificity } \\
(95 \% \mathrm{CI})\end{array}$ & $\begin{array}{l}\text { Positive LR } \\
(95 \% \mathrm{Cl})\end{array}$ & $\begin{array}{l}\text { DOR } \\
(95 \% \mathrm{CI})\end{array}$ & $\begin{array}{l}\text { AUC } \\
(95 \% \mathrm{CI})\end{array}$ \\
\hline \multicolumn{7}{|c|}{ Linked color imaging (LCI): per-biopsy analysis } \\
\hline $\begin{array}{l}\text { Overall (with- } \\
\text { out ME) }\end{array}$ & 2 & $0.73(0.65-0.81)$ & $0.92(0.87-0.96)$ & $8.89(2.49-31.68)$ & $35.09(16.20-75.98)$ & - \\
\hline \multicolumn{7}{|c|}{ Blue laser imaging (BLI): per-patient analysis } \\
\hline Overall & 2 & $0.78(0.67-0.87)$ & $0.83(0.75-0.89)$ & $7.48(0.37-150.36)$ & $32.12(0.66-1569.3)$ & - \\
\hline With ME & 1 & $0.89(0.74-0.97)$ & $0.97(0.89-0.99)$ & $28.44(7.23-111.82)$ & $248(43.09-1427.4)$ & - \\
\hline Without ME & 1 & $0.68(0.52-0.82)$ & $0.69(0.57-0.80)$ & $2.22(1.46-3.38)$ & $4.85(2.09-11.26)$ & - \\
\hline
\end{tabular}

BLI

Three studies evaluated BLI, including 736 patients [52-54]. Pooled analysis was possible for two of them, reaching a sensitivity and specificity of 0.78 and 0.83 , respectively, for GIM detection. Only one study evaluated BLI without high magnification, showing a low sensitivity and specificity $(0.68$ and 0.69 , respectively), but possible reasons for this low performance level were not discussed in the study. In contrast, the two studies that applied BLI with high magnification obtained a high accuracy and the authors concluded that the results were similar to those obtained with ME-NBI in previous reports.

\section{LCI}

Two studies evaluated the accuracy of LCI for GIM, including 176 patients $[55,56]$. The pooled sensitivity and specificity were 0.73 and 0.92 , respectively. Regarding the appearance of GIM, the authors speculated that the "lavender-color sign" in $\mathrm{LCl}$ corresponds to the "bluish-whitish area" observed in NBI as both probably have the same explanation, this being differences in the light reflectance of the brush border.

\section{Discussion}

Gastric cancer is the fifth most common cancer worldwide, with a high lethality rate [58], mainly owing to its late diagnosis. Screening programs have been applied for many years in high incidence populations, improving the survival rate. Although these programs can also be cost-effective in intermediate risk countries $[59,60]$, they have still not been implemented, and current recommendations suggest the diagnosis and surveillance of individuals with extensive preneoplastic conditions through the use of IEE [59,61-63]. This approach allows the possibility of offering an endoscopic treatment instead of gastric surgery, so avoiding the associated morbidity and mortality [59, 62, 64, 65].

According to the IEE technology being used, descriptors for preneoplastic conditions or EGC have been modified over time. For instance, with WLE, GIM was first described as "ash-colored nodular changes" by Kaminishi et al. [66] and as a "motley patchy erythema" by Nagata et al. [67]. With NBI, new markers were described such as "bluish-whitish areas" [8] and, when using ME-NBI, LBCs can be seen in these areas [5]. However, the accuracy of these technologies changes according to which endoscopic marker is analyzed, so it is necessary to clearly identify the descriptors that are associated with higher IEE diagnostic accuracy. Furthermore, current Al technologies have high false positive/negative rates $[68,69]$, a possible explanation for which is a lack of standardization of patterns. Therefore, the results of this meta-analysis can also aid in the development of better Al technologies for detection and characterization of gastric preneoplastic conditions and neoplastic lesions.

Previous meta-analyses have assessed the performance of $\mathrm{NBI}$ for diagnosing GIM and dysplasia [13,70,71]; however, there are fewer studies evaluating other IEE technologies and the possible factors that influence their performance.

This meta-analysis confirms the high accuracy of NBI (with or without high magnification) for GIM and also for EGC (but for this outcome specificity was higher with high magnification). In the studies with ME-NBI, the use of the VS classification also seemed to improve specificity compared with other endoscopic criteria (0.98 vs. 0.94$)$. Authors from the non-VS classification studies established the diagnosis according to irregularities on the microvascular/microsurface pattern, although two of them analyzed these patterns in demarcated or circumscribed lesions without specifying if they were really evaluating a demarcation line or not. Our meta-analysis supports the results from previous studies that suggest the VS classification is an effective criterion to diagnose intestinal-type EGC [72]. A slightly higher specificity ( $2 \%$ increase) for EGC was found in the studies that did not use WLE before NBI. However, even if WLE does not add to the characterization, it is undoubtedly useful for detection and can provide additional clues to endoscopic diagnosis and prediction of deep submucosal invasion (e.g. morphological changes, redness, convergence of mucosal folds) [72].

Regarding GIM, the accuracy of non-ME-NBI was similar to that of ME-NBI, and the best diagnostic measures were even ob- 
- Table 4 Pooled analysis of results for dysplasia/early gastric cancer.

\begin{tabular}{|c|c|c|c|c|c|c|}
\hline Covariates & $\begin{array}{l}\text { Num- } \\
\text { ber of } \\
\text { stud- } \\
\text { ies }\end{array}$ & $\begin{array}{l}\text { Sensitivity } \\
(95 \% \mathrm{CI})\end{array}$ & $\begin{array}{l}\text { Specificity } \\
\text { (95\% Cl) }\end{array}$ & $\begin{array}{l}\text { Positive LR } \\
(95 \% \mathrm{Cl})\end{array}$ & $\begin{array}{l}\text { DOR } \\
(95 \% \mathrm{Cl})\end{array}$ & $\begin{array}{l}\text { AUC } \\
(95 \% \mathrm{Cl})\end{array}$ \\
\hline
\end{tabular}

Narrow-band imaging (NBI) for early gastric cancer: per-biopsy analysis

\begin{tabular}{|c|c|c|c|c|c|c|}
\hline Overall & 19 & $0.87(0.84-0.89)$ & $0.97(0.97-0.98)$ & $14.03(7.21-27.28)$ & $107.38(45.91-251.15)$ & $0.95(0.93-0.98)$ \\
\hline \multicolumn{7}{|c|}{ High magnification (ME) } \\
\hline Overall & 17 & $0.87(0.84-0.89)$ & $0.97(0.97-0.98)$ & $15.20(7.31-31.58)$ & $114.08(46.30-281.08)$ & $0.96(0.93-0.98)$ \\
\hline WLE & 8 & $0.88(0.88-0.92)$ & $0.96(0.95-0.97)$ & $18.96(10.21-35.20)$ & $158.49(67.49-372.20)$ & $0.98(0.96-1.00)$ \\
\hline Non-WLE & 9 & $0.86(0.84-0.89)$ & $0.98(0.97-0.98)$ & $12.12(3.49-42.05)$ & $80.78(19.26-338.86)$ & $0.94(0.90-0.98)$ \\
\hline $\begin{array}{l}\text { VS classifica- } \\
\text { tion }\end{array}$ & 14 & $0.86(0.83-0.88)$ & $0.98(0.97-0.98)$ & $14.56(6.01-35.30)$ & $97.81(34.51-277.22)$ & $0.95(0.91-0.98)$ \\
\hline $\begin{array}{l}\text { Non-VS clas- } \\
\text { sification }\end{array}$ & 3 & $0.94(0.88-0.98)$ & $0.94(0.92-0.96)$ & $17.31(5.30-56.57)$ & $223.79(73.91-677.64)$ & $0.98(0.97-1.00)$ \\
\hline \multicolumn{7}{|l|}{ Non-ME } \\
\hline Overall & 2 & $0.91(0.59-1.00)$ & $0.84(0.78-0.90)$ & $7.12(1.88-26.92)$ & $60.34(9.26-393.14)$ & - \\
\hline WLE & 1 & $0.88(0.47-1.00)$ & $0.93(0.81-0.99)$ & $12.83(4.17-39.46)$ & $95.67(8.67-1055.5)$ & - \\
\hline Non-WLE & 1 & $1.00(0.29-1.00)$ & $0.81(0.73-0.88)$ & $4.55(2.69-7.69)$ & $29.40(1.47-589.72)$ & - \\
\hline $\begin{array}{l}\text { VS classifi- } \\
\text { cation }\end{array}$ & 1 & $0.88(0.47-1.00)$ & $0.93(0.81-0.99)$ & $12.83(4.17-39.46)$ & $95.67(8.67-1055.5)$ & - \\
\hline $\begin{array}{l}\text { Non-VS clas- } \\
\text { sification }\end{array}$ & 1 & $1.00(0.29-1.00)$ & $0.81(0.73-0.88)$ & $4.55(2.69-7.69)$ & $29.40(1.47-589.72)$ & - \\
\hline \multicolumn{7}{|c|}{ Depressed-type lesions } \\
\hline Overall & 6 & $0.88(0.80-0.93)$ & $0.96(0.93-0.97)$ & $17.41(10.69-28.36)$ & $143.83(38.80-533.23)$ & $0.99(0.98-1.00)$ \\
\hline $\mathrm{ME}$ & 5 & $0.88(0.80-0.93)$ & $0.96(0.94-0.97)$ & $18.08(10.11-32.32)$ & $160.53(32.98-781.36)$ & $0.99(0.98-1.00)$ \\
\hline Non-ME & 1 & $0.88(0.47-1.00)$ & $0.93(0.81-0.99)$ & $12.83(4.17-39.46)$ & $95.67(8.67-1055.5)$ & - \\
\hline ME-WLE & 5 & $0.86(0.76-0.92)$ & $0.96(0.94-0.97)$ & $18.57(9.96-34.65)$ & $170.69(26.55-1097.4)$ & $0.99(0.96-1.01)$ \\
\hline ME-Non-WLE & 0 & - & - & - & - & - \\
\hline $\begin{array}{l}\text { ME-VS clas- } \\
\text { sification }\end{array}$ & 4 & $0.87(0.78-0.93)$ & $0.96(0.94-0.98)$ & $17.55(7.25-42.49)$ & $151.80(20.37-1131.18)$ & $0.99(0.96-1.01)$ \\
\hline $\begin{array}{l}\text { ME-Non-VS } \\
\text { classification }\end{array}$ & 1 & $0.93(0.66-1.00)$ & $0.95(0.90-0.97)$ & $17.36(9.34-32.29)$ & $230.10(27.31-1939.00)$ & - \\
\hline \multicolumn{7}{|c|}{ Elevated-type lesions } \\
\hline Overall & 3 & $0.88(0.82-0.92)$ & $0.87(0.80-0.92)$ & $6.74(0.96-47.45)$ & $45.92(3.85-547.59)$ & $0.94(0.85-1.03)$ \\
\hline ME & 3 & $0.88(0.82-0.92)$ & $0.87(0.80-0.92)$ & $6.74(0.96-47.45)$ & $45.92(3.85-547.59)$ & $0.94(0.85-1.03)$ \\
\hline Non-ME & 0 & - & - & - & - & - \\
\hline ME-WLE & 0 & - & - & - & - & - \\
\hline ME-Non-WLE & 3 & $0.88(0.82-0.92)$ & $0.87(0.80-0.92)$ & $6.74(0.96-47.45)$ & $45.92(3.85-547.59)$ & $0.94(0.85-1.03)$ \\
\hline $\begin{array}{l}\text { ME-VS clas- } \\
\text { sification }\end{array}$ & 3 & $0.88(0.82-0.92)$ & $0.87(0.80-0.92)$ & $6.74(0.96-47.45)$ & $45.92(3.85-547.59)$ & $0.94(0.85-1.03)$ \\
\hline $\begin{array}{l}\text { ME-Non-VS } \\
\text { classification }\end{array}$ & 0 & $0.88(0.82-0.92)$ & $0.87(0.80-0.92)$ & $6.74(0.96-47.45)$ & $45.92(3.85-547.59)$ & $0.94(0.85-1.03)$ \\
\hline \multicolumn{7}{|c|}{ Trimodal imaging (TMI) for dysplasia: per-biopsy analysis } \\
\hline Overall & 2 & $0.93(0.85-0.98)$ & $0.98(0.92-1.00)$ & $35.24(10.06-123.46)$ & $565.81(93.32-3430.6)$ & \\
\hline
\end{tabular}



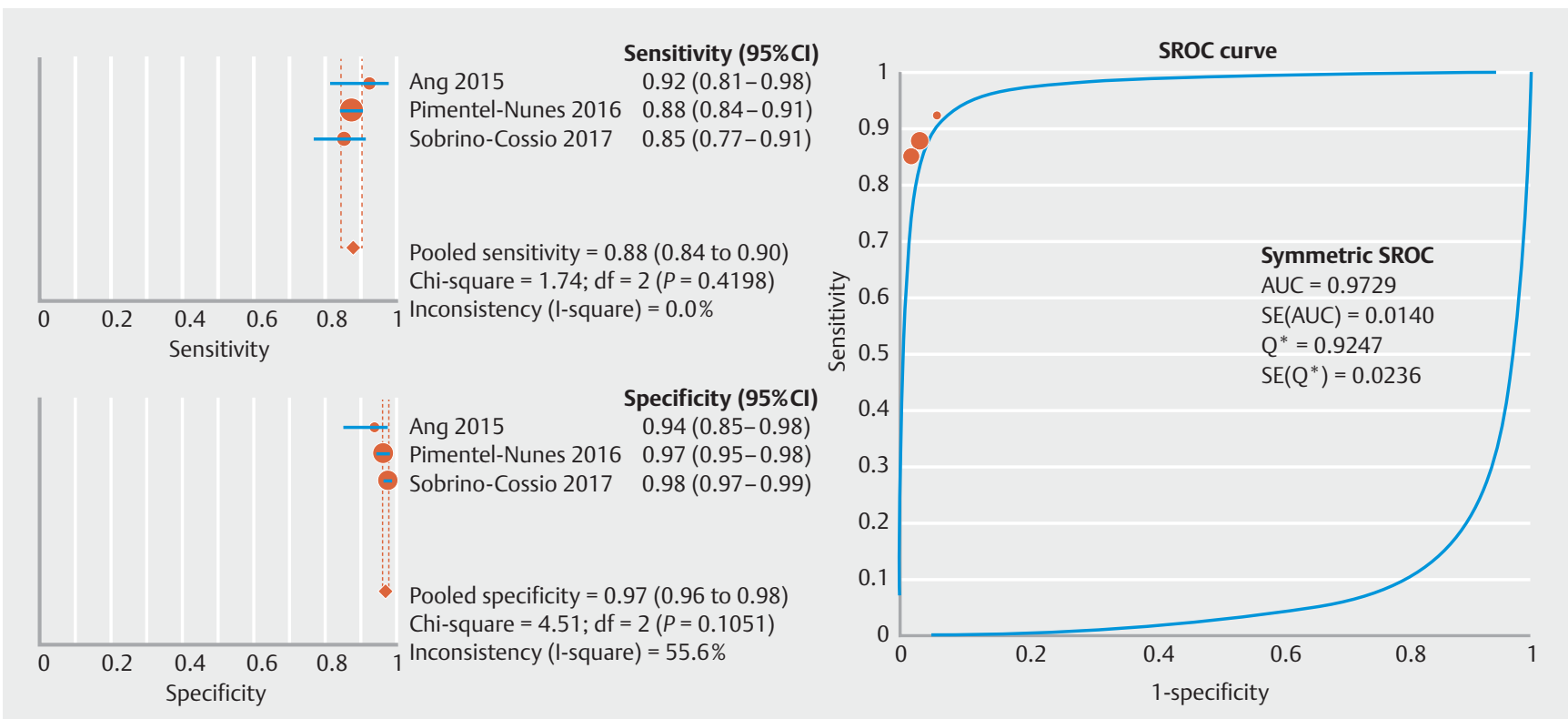

- Fig. 3 Narrow-band imaging pooled analysis for gastric intestinal metaplasia: accuracy of tubulovillous pattern \pm light blue crest, without high magnification, on per-biopsy basis. $\mathrm{Cl}$, confidence interval; SROC, summary receiver operating curve; AUC, area under the curve; SE, standard error; $Q^{*}, Q$ index; df, degrees of freedom.

tained using tubulovillous pattern without high magnification (sensitivity of 0.88 , specificity of 0.97 , absent-to-moderate heterogeneity). Under high magnification, the presence of LBCs as the only marker for GIM obtained lower specificity when compared with the use of other markers (0.89 vs. 0.96). LBC definition also differed between studies. Therefore, we consider that tubulovillous pattern is the most adequate marker to identify GIM. Moreover, tubulovillous pattern can be effectively detected even without high magnification, which makes it suitable for widespread adoption because of the limited availability of high magnification in some centers.

Regarding other technologies, pooled analysis was only possible for some of them owing to the low number of studies included. Although it was not possible to perform a comparison between IEE technologies, current evidence suggests that NBI is the most effective technology to detect gastric preneoplastic conditions and EGC [1]. The high false positive rate of AFI may improve with TMI, but none of these technologies were demonstrated to be superior to ME-NBI. The lack of standardization of FICE settings makes it difficult to perform comparative studies, and i-SCAN seems not to be adequate for vascular pattern assessment [50]. Although one study suggested that PCLE added to the specificity when compared with FICE alone [51], the diagnostic measures obtained are not superior to the pooled accuracy achieved with virtual chromoendoscopy, meaning its value for this outcome remains questionable.

The main difference between NBI and the above-mentioned technologies is that it is a narrowed-spectrum technology by filtering illumination light, which provides good visualization of the microsurface/microvascular pattern. BLI shares the same physical principle but, instead of having an optical filter, it combines two laser lights (blue laser imaging) or changes the light intensity of different LED lights (blue light imaging) to obtain the narrow-band light. As a result, BLI delivers images similar to NBI, and it is expected that results from the two technologies will be equivalent. Although some studies reported comparable results between BLI and NBI, they were performed under high magnification, and mostly in Eastern countries. A recent study also reported excellent results with BLI without high magnification to diagnose GIM [73]; nevertheless, more studies evaluating BLI without high magnification, especially in Western countries, are needed to reach definite conclusions.

None of the studies showed a specific pattern for atrophic gastritis, and the accuracy for detecting this condition was particularly low. However, GIM is a more reliable marker of gastric cancer risk and its endoscopic descriptors are more consistent and reproducible, therefore, unless new accurate atrophic gas-

\section{Table 5 List of recommendations.}

\section{Image-enhanced endoscopy (IEE) technologies}

Current evidence suggests narrow-band imaging (NBI) to be the most effective IEE technology to detect gastric intestinal metaplasia (GIM) and cancerous lesions

Owing to blue laser/light imaging (BLI) and NBI sharing the same physical principle, it is expected that results will be equivalent

\section{Preneoplastic conditions and neoplastic lesions}

There is a necessity to reassess descriptors for atrophic gastritis Tubulovillous pattern is the most effective marker to detect GIM Vessel plus surface (VS) classification may be useful to characterize cancerous lesions

Magnifying endoscopy can be helpful even though not required for GIM assessment 

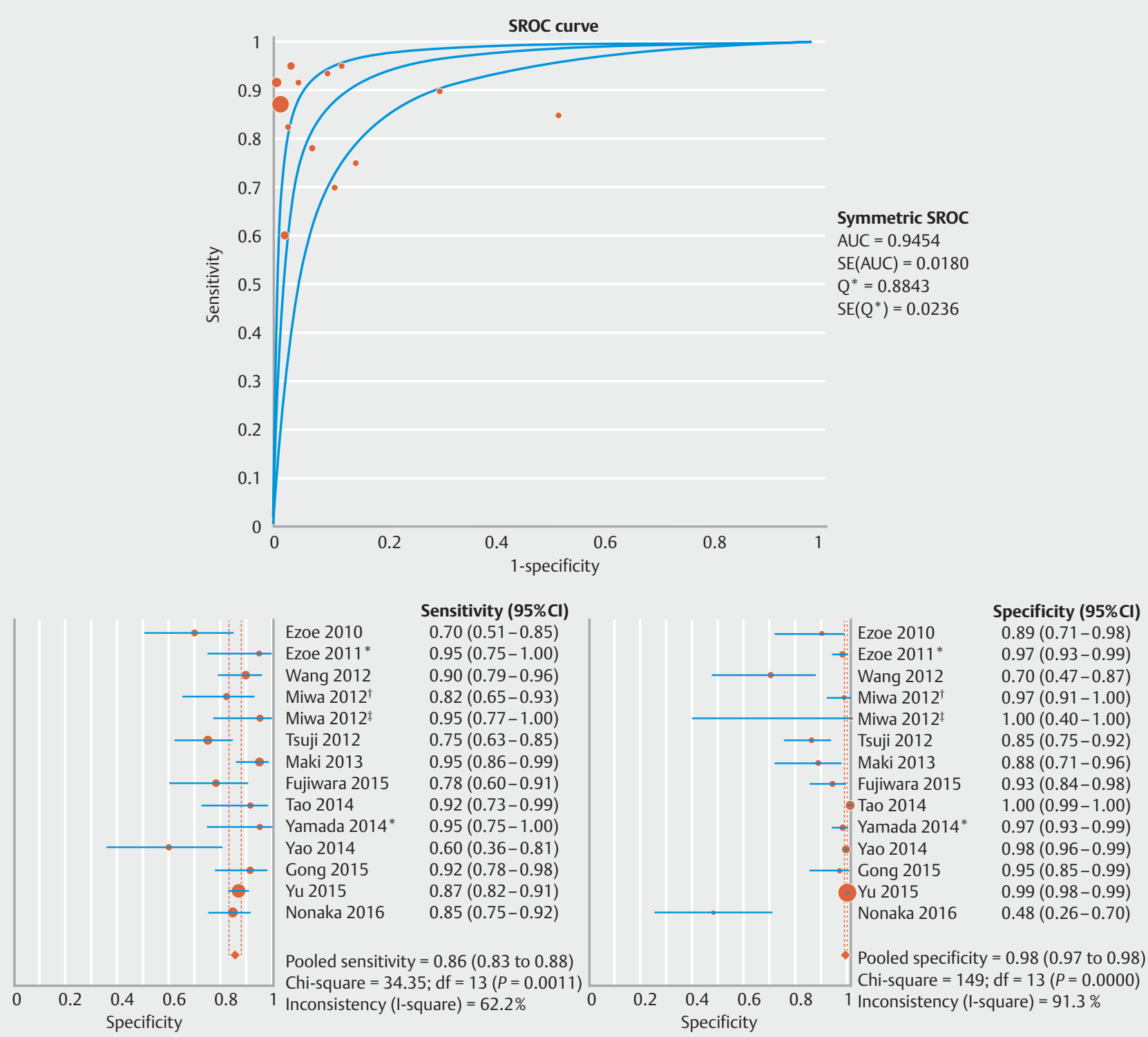

Fig. 4 Narrow-band imaging pooled analysis for early gastric cancer: accuracy of the vessel plus surface classification under high magnification, on a per-biopsy basis. $\mathrm{Cl}$, confidence interval; SROC, summary receiver operating curve; AUC, area under the curve; SE, standard error; $\mathrm{Q}^{*}$, $\mathrm{Q}$ index; df, degrees of freedom. ${ }^{*}$ WLE followed by NBI. ${ }^{\dagger}$ Elevated lesions. ${ }^{\ddagger}$ Depressed lesions.

tritis classifications emerge, GIM seems to be the best endoscopic indicator for stratification of gastric cancer risk.

Some limitations have to be considered. First, most of the studies were carried out in Eastern countries, namely Japan, which is considered a high risk country for the incidence of gastric cancer; this may induce an enriched study population. Second, there was high heterogeneity among studies regarding descriptors, lesions/area assessed, and population, which could lead to a mis- or overdiagnosis. Some of these affected the quality of studies, especially for dysplasia/EGC, and this must to be taken into account in the assessment of the results. In spite of these assumptions, our initial analysis considering studies with low risk of bias obtained the same results in terms of accuracy and heterogeneity; moreover, the investigation of the possible influence of different covariates was not possible owing to the low number of studies.

In conclusion, our study confirms the high accuracy of NBI for GIM and EGC ( $\triangleright$ Table 5). There is a necessity for mucosal pattern to be reassessed for atrophic gastritis; until new atrophic gastritis classifications emerge, GIM is the most effective marker to evaluate EGC risk. As the presence of the tubulovillous pattern is the most relevant pattern for detecting GIM, this should be used in current practice, and it can be effectively evaluated without using high magnification. This feature, along with the VS classification, seems to be consistent and usable for new IEE technologies, such as BLI (with the recently emerged multi-LED technology) and Al, looking toward improving the diagnosis of preneoplastic conditions and cancerous lesions. 


\section{Competing interests}

The authors declare that they have no conflict of interest.

References

[1] East JE, Vleugels JL, Roelandt P et al. Advanced endoscopic imaging: European Society of Gastrointestinal Endoscopy (ESGE) Technology Review. Endoscopy 2016; 48: 1029-1045

[2] Barbeiro S, Libanio D, Castro R et al. Narrow-band imaging: clinical application in gastrointestinal endoscopy. GE Port J Gastroenterol 2018; 26: 40-53

[3] Dias-Silva D, Pimentel-Nunes P, Magalhaes J et al. The learning curve for narrow-band imaging in the diagnosis of precancerous gastric lesions by using Web-based video. Gastrointest Endosc 2014; 79: 910 920

[4] Rodriguez-Carrasco M, Libanio D, Dinis-Ribeiro M et al. Where should gastric biopsies be performed when areas of intestinal metaplasia are observed? Endosc Int Open 2019; 7: 1636-1639

[5] Uedo $\mathrm{N}$, Ishihara $\mathrm{R}$, lishi $\mathrm{H}$ et al. A new method of diagnosing gastric intestinal metaplasia: narrow-band imaging with magnifying endoscopy. Endoscopy 2006; 38: 819-824

[6] Nakayoshi T, Tajiri H, Matsuda K et al. Magnifying endoscopy combined with narrow band imaging system for early gastric cancer: correlation of vascular pattern with histopathology (including video). Endoscopy 2004; 36: 1080-1084

[7] Tanaka K, Toyoda H, Kadowaki S et al. Surface pattern classification by enhanced-magnification endoscopy for identifying early gastric cancers. Gastrointest Endosc 2008; 67: 430-437

[8] Capelle LG, Haringsma J, de Vries AC et al. Narrow band imaging for the detection of gastric intestinal metaplasia and dysplasia during surveillance endoscopy. Dig Dis Sci 2010; 55: 3442-3448

[9] Rerknimitr R, Imraporn B, Klaikeaw $\mathrm{N}$ et al. Non-sequential narrow band imaging for targeted biopsy and monitoring of gastric intestinal metaplasia. World J Gastroenterol 2011; 17: 1336-1342

[10] Pimentel-Nunes P, Dinis-Ribeiro M, Soares JB et al. A multicenter validation of an endoscopic classification with narrow band imaging for gastric precancerous and cancerous lesions. Endoscopy 2012; 44: 236-246

[11] Savarino E, Corbo M, Dulbecco P et al. Narrow-band imaging with magnifying endoscopy is accurate for detecting gastric intestinal metaplasia. World J Gastroenterol 2013; 19: 2668-2675

[12] Boeriu A, Boeriu C, Drasovean S et al. Narrow-band imaging with magnifying endoscopy for the evaluation of gastrointestinal lesions. World J Gastrointest Endosc 2015; 7: 110-120

[13] Kikuste I, Marques-Pereira R, Monteiro-Soares M et al. Systematic review of the diagnosis of gastric premalignant conditions and neoplasia with high-resolution endoscopic technologies. Scand J Gastroenterol 2013; 48: 1108-1117

[14] Tahara T, Shibata T, Nakamura M et al. Gastric mucosal pattern by using magnifying narrow-band imaging endoscopy clearly distinguishes histological and serological severity of chronic gastritis. Gastrointest Endosc 2009; 70: 246-253

[15] An JK, Song GA, Kim GH et al. Marginal turbid band and light blue crest, signs observed in magnifying narrow-band imaging endoscopy, are indicative of gastric intestinal metaplasia. BMC Gastroenterol 2012; 12: 169

[16] Bansal A, Ulusarac O, Mathur S et al. Correlation between narrow band imaging and nonneoplastic gastric pathology: a pilot feasibility trial. Gastrointest Endosc 2008; 67: 210-216
[17] Liu H, Wu J, Lin XC et al. Evaluating the diagnoses of gastric antral lesions using magnifying endoscopy with narrow-band imaging in a Chinese population. Dig Dis Sci 2014; 59: 1513-1519

[18] Ang TL, Pittayanon R, Lau JY et al. A multicenter randomized comparison between high-definition white light endoscopy and narrow band imaging for detection of gastric lesions. Eur J Gastroenterol Hepatol 2015; 27: 1473-1478

[19] Lage J, Pimentel-Nunes P, Figueiredo PC et al. Light-NBI to identify high-risk phenotypes for gastric adenocarcinoma: do we still need biopsies? Scand J Gastroenterol 2016; 51: 501-506

[20] Pimentel-Nunes P, Libanio D, Lage J et al. A multicenter prospective study of the real-time use of narrow-band imaging in the diagnosis of premalignant gastric conditions and lesions. Endoscopy 2016; 48: 723-730

[21] Kanemitsu T, Yao K, Nagahama T et al. Extending magnifying NBI diagnosis of intestinal metaplasia in the stomach: the white opaque substance marker. Endoscopy 2017; 49: 529-535

[22] Sha J, Wang P, Zhu B et al. Acetic acid enhanced narrow band imaging for the diagnosis of gastric intestinal metaplasia. PloS One 2017; 12: e0170957

[23] Tahara T, Tahara S, Tuskamoto T et al. Magnifying NBI patterns of gastric mucosa after Helicobacter pylori eradication and its potential link to the gastric cancer risk. Dig Dis Sci 2017; 62: 2421-2427

[24] Sobrino-Cossio S, Abdo Francis JM, Emura F et al. Efficacy of narrowband imaging for detecting intestinal metaplasia in adult patients with symptoms of dyspepsia. Rev Gastroenterol Mex 2018; 83: 245252

[25] Esposito G, Pimentel-Nunes P, Angeletti S et al. Endoscopic grading of gastric intestinal metaplasia (EGGIM): a multicenter validation study. Endoscopy 2019; 51: 515-521

[26] Lim LG, Yeoh KG, Srivastava S et al. Comparison of probe-based confocal endomicroscopy with virtual chromoendoscopy and white-light endoscopy for diagnosis of gastric intestinal metaplasia. Surg Endosc 2013; 27 : 4649-4655

[27] Ezoe $\mathrm{Y}$, Muto M, Horimatsu T et al. Magnifying narrow-band imaging versus magnifying white-light imaging for the differential diagnosis of gastric small depressive lesions: a prospective study. Gastrointest Endosc 2010; 71: 477-484

[28] Ezoe $\mathrm{Y}$, Muto $\mathrm{M}$, Uedo $\mathrm{N}$ et al. Magnifying narrowband imaging is more accurate than conventional white-light imaging in diagnosis of gastric mucosal cancer. Gastroenterology 2011; 141: 2017-2025

[29] Kato M, Kaise M, Yonezawa J et al. Magnifying endoscopy with narrow-band imaging achieves superior accuracy in the differential diagnosis of superficial gastric lesions identified with white-light endoscopy: a prospective study. Gastrointest Endosc 2010; 72: $523-$ 529

[30] Wang SF, Yang YS, Yuan J et al. Magnifying endoscopy with narrowband imaging may improve diagnostic accuracy of differentiated gastric intraepithelial neoplasia: a feasibility study. Chin Med J 2012; 125: 728-732

[31] Li HY, Dai J, Xue HB et al. Application of magnifying endoscopy with narrow-band imaging in diagnosing gastric lesions: a prospective study. Gastrointest Endosc 2012; 76: 1124-1132

[32] Miwa K, Doyama H, Ito R et al. Can magnifying endoscopy with narrow band imaging be useful for low grade adenomas in preoperative biopsy specimens? Gastric Cancer 2012; 15: 170-178

[33] Tsuji Y, Ohata K, Sekiguchi M et al. Magnifying endoscopy with narrow-band imaging helps determine the management of gastric adenomas. Gastric Cancer 2012; 15: 414-418

[34] Maki S, Yao K, Nagahama T et al. Magnifying endoscopy with narrowband imaging is useful in the differential diagnosis between lowgrade adenoma and early cancer of superficial elevated gastric lesions. Gastric Cancer 2013; 16: 140-146 
[35] Kawai T, Yanagizawa K, Naito $S$ et al. Evaluation of gastric cancer diagnosis using new ultrathin transnasal endoscopy with narrow-band imaging: preliminary study. J Gastroenterol Hepatol 2014; 29: 33-36

[36] Tao G, Xing-Hua L, Ai-Ming Y et al. Enhanced magnifying endoscopy for differential diagnosis of superficial gastric lesions identified with white-light endoscopy. Gastric Cancer 2014; 17: 122-129

[37] Yamada S, Doyama H, Yao K et al. An efficient diagnostic strategy for small, depressed early gastric cancer with magnifying narrow-band imaging: a post-hoc analysis of a prospective randomized controlled trial. Gastrointest Endosc 2014; 79: 55-63

[38] Yao K, Doyama H, Gotoda T et al. Diagnostic performance and limitations of magnifying narrow-band imaging in screening endoscopy of early gastric cancer: a prospective multicenter feasibility study. Gastric Cancer 2014; 17: 669-679

[39] Fujiwara S, Yao K, Nagahama T et al. Can we accurately diagnose minute gastric cancers $(<1=5 \mathrm{~mm})$ ? Chromoendoscopy (CE) vs magnifying endoscopy with narrow band imaging (M-NBI) Gastric Cancer 2015; 18: 590-596

[40] Gong S, Xue HB, Ge ZZ et al. Value of magnifying endoscopy with narrow-band imaging and confocal laser endomicroscopy in detecting gastric cancerous lesions. Medicine 2015; 94: e1930

[41] Yu H, Yang AM, Lu XH et al. Magnifying narrow-band imaging endoscopy is superior in diagnosis of early gastric cancer. World J Gastroenterol 2015; 21: 9156-9162

[42] Nonaka T, Inamori M, Honda Y et al. Can magnifying endoscopy with narrow-band imaging discriminate between carcinomas and low grade adenomas in gastric superficial elevated lesions? Endosc Int Open 2016; 4: 1203-1210

[43] Inoue T, Uedo N, Ishihara R et al. Autofluorescence imaging videoendoscopy in the diagnosis of chronic atrophic fundal gastritis. J Gastroenterol 2010; 45: 45-51

[44] So J, Rajnakova A, Chan YH et al. Endoscopic tri-modal imaging improves detection of gastric intestinal metaplasia among a high-risk patient population in Singapore. Dig Dis Sci 2013; 58: 3566-3575

[45] Shi J, Jin N, Li Y et al. Clinical study of autofluorescence imaging combined with narrow band imaging in diagnosing early gastric cancer and precancerous lesions. J BUON 2015; 20: 1215-1222

[46] Kobayashi M, Tajiri H, Seike E et al. Detection of early gastric cancer by a real-time autofluorescence imaging system. Cancer Lett 2001; 165: $155-159$

[47] Kato M, Kaise M, Yonezawa J et al. Autofluorescence endoscopy versus conventional white light endoscopy for the detection of superficial gastric neoplasia: A prospective comparative study. Endoscopy 2007; 39: 937-941

[48] Kato M, Kaise M, Yonezawa J et al. Trimodal imaging endoscopy may improve diagnostic accuracy of early gastric neoplasia: a feasibility study. Gastrointest Endosc 2009; 70: 899-906

[49] Imaeda H, Hosoe N, Kashiwagi K et al. Surveillance using trimodal imaging endoscopy after endoscopic submucosal dissection for superficial gastric neoplasia. World J Gastroenterol 2014; 20: 1631116317

[50] Li CQ, Li Y, Zuo XL et al. Magnified and enhanced computed virtual chromoendoscopy in gastric neoplasia: a feasibility study. World J Gastroenterol 2013; 19: 4221-4227

[51] Pittayanon R, Rerknimitr R, Wisedopas $\mathrm{N}$ et al. Flexible spectral imaging color enhancement plus probe-based confocal laser endomicroscopy for gastric intestinal metaplasia detection. J Gastroenterol Hepatol 2013; 28: 1004-1009

[52] Dohi O, Yagi N, Majima A et al. Diagnostic ability of magnifying endoscopy with blue laser imaging for early gastric cancer: a prospective study. Gastric Cancer 2017; 20: 297-303
[53] Chen H, Liu Y, Lu Y et al. Ability of blue laser imaging with magnifying endoscopy for the diagnosis of gastric intestinal metaplasia. Lasers Med Sci 2018; 33: 1757-1762

[54] Chen H, Wu X, Liu Y et al. Blue laser imaging with acetic acid enhancement improved the detection rate of gastric intestinal metaplasia. Lasers Med Sci 2019; 34: 555-559

[55] Fukuda H, Miura Y, Osawa $\mathrm{H}$ et al. Linked color imaging can enhance recognition of early gastric cancer by high color contrast to surrounding gastric intestinal metaplasia. J Gastroenterol 2019; 54: 396406

[56] Ono S, Kato M, Tsuda M et al. Lavender color in linked color imaging enables noninvasive detection of gastric intestinal metaplasia. Digestion 2018; 98: 222-230

[57] Yao K, Anagnostopoulos GK, Ragunath K. Magnifying endoscopy for diagnosing and delineating early gastric cancer. Endoscopy 2009; 41: 462-467

[58] Bray F, Ferlay J, Soerjomataram I et al. Global cancer statistics 2018: GLOBOCAN estimates of incidence and mortality worldwide for 36 cancers in 185 countries. CA Cancer J Clin 2018; 68: 394-424

[59] Pimentel-Nunes P, Libanio D, Marcos-Pinto R et al. Management of epithelial precancerous conditions and lesions in the stomach (MAPS II): European Society of Gastrointestinal Endoscopy (ESGE), European Helicobacter and Microbiota Study Group (EHMSG), European Society of Pathology (ESP), and Sociedade Portuguesa de Endoscopia Digestiva (SPED) guideline update 2019. Endoscopy 2019; 51: 365-388

[60] Areia M, Spaander MC, Kuipers EJ et al. Endoscopic screening for gastric cancer: A cost-utility analysis for countries with an intermediate gastric cancer risk. United European Gastroenterol J 2018; 6: 192-202

[61] Dinis-Ribeiro M, Areia M, de Vries AC et al. Management of precancerous conditions and lesions in the stomach (MAPS): guideline from the European Society of Gastrointestinal Endoscopy (ESGE), European Helicobacter Study Group (EHSG), European Society of Pathology (ESP), and the Sociedade Portuguesa de Endoscopia Digestiva (SPED). Endoscopy 2012; 44: 74-94

[62] Pimentel-Nunes P, Libanio D, Dinis-Ribeiro M. Evaluation and management of gastric superficial neoplastic lesions. GE Port J Gastroenterol 2017; 24: 8-21

[63] Banks M, Graham D, Jansen M et al. British Society of Gastroenterology guidelines on the diagnosis and management of patients at risk of gastric adenocarcinoma. Gut 2019; 68: 1545-1575

[64] Pimentel-Nunes P, Dinis-Ribeiro M, Ponchon T et al. Endoscopic submucosal dissection: European Society of Gastrointestinal Endoscopy (ESGE) Guideline. Endoscopy 2015; 47: 829-854

[65] Libanio D, Braga V, Ferraz S et al. Prospective comparative study of endoscopic submucosal dissection and gastrectomy for early neoplastic lesions including patients' perspectives. Endoscopy 2019; 51: 30-39

[66] Kaminishi M, Yamaguchi H, Nomura S et al. Endoscopic classification of chronic gastritis based on a pilot study by the research society for gastritis. Dig Endosc 2002; 14: 138-151

[67] Nagata N, Shimbo T, Akiyama J et al. Predictability of gastric intestinal metaplasia by mottled patchy erythema seen on endoscopy. Gastroenterology Res 2011; 4: 203-209

[68] Hirasawa T, Aoyama K, Tanimoto T et al. Application of artificial intelligence using a convolutional neural network for detecting gastric cancer in endoscopic images. Gastric Cancer 2018; 21: 653-660

[69] Mori Y, Kudo SE, Mohmed HEN et al. Artificial intelligence and upper gastrointestinal endoscopy: Current status and future perspective. Dig Endosc 2019; 31: 378-388 
[70] Song J, Zhang J, Wang J et al. Meta-analysis: narrow band imaging for diagnosis of gastric intestinal metaplasia. PloS One 2014; 9: e94869

[71] Wang L, Huang W, Du J et al. Diagnostic yield of the light blue crest sign in gastric intestinal metaplasia: a meta-analysis. PloS One 2014; 9: e92874
[72] Muto M, Yao K et al. Magnifying endoscopy simple diagnostic algorithm for early gastric cancer (MESDA-G). Dig Endosc 2016; 28: 379393

[73] Castro R, Rodriguez M, Libânio D et al. Reliability and accuracy of blue light imaging for staging of intestinal metaplasia in the stomach. Scand J Gastroenterol 2019; 54: 1301-1305 